\title{
Activation of $\mathrm{D}_{2}$-like receptors induces sympathetic climactic-like responses in male and female anaesthetised rats
}

\author{
${ }^{1}$ S.A. Stafford \& *, J.H. Coote \\ ${ }^{1}$ Division of Neuroscience, The Medical School, University of Birmingham, Edgbaston, Birmingham B15 2TT
}

1 In anaesthetised male rats an intravenous (i.v.) injection of $p$-chloroamphetamine (PCA) produced a specific patterned bursting response in the sympathetic vas deferens nerve (VDN) that corresponds to ejaculation. In the present, study selective dopamine agonists and antagonists were used to investigate whether dopaminergic mechanisms influence the generation of this ejaculatory-related response.

2 Administration of a mixed $D_{1 / 2}$ receptor agonist $\left(0.1-1.0 \mathrm{mg} \mathrm{kg}^{-1}\right.$ apomorphine i.v.) also evoked the characteristic bursting pattern responses in the VDN. Similar, but fewer, burst pattern responses could also be evoked by a selective $\mathrm{D}_{2 / 3}$ receptor agonist $\left(0.1-2.0 \mathrm{mg} \mathrm{kg}^{-1}\right.$ piribedil). Responses to $1.0 \mathrm{mg} \mathrm{kg}^{-1}$ apomorphine were blocked by pretreatments with either $0.5 \mathrm{mg} \mathrm{kg}^{-1}$ remoxipride $\left(\mathrm{D}_{2}\right.$ receptor antagonist) or $0.5 \mathrm{mg} \mathrm{kg}^{-1}$ nafadotride $\left(\mathrm{D}_{3}\right.$ receptor antagonist), suggesting that $\mathrm{D}_{2}$-like receptors were involved.

3 Responses could not be evoked by i.v. injections of apomorphine $\left(1.0 \mathrm{mg} \mathrm{kg}^{-1}\right)$ in anaesthetised male rats with a midthoracic spinal section, indicating that activation of $\mathrm{D}_{2}$-like receptors at supraspinal sites leads to an increase in the excitability of the lumbosacral pattern generator for ejaculation.

4 In anaesthetised female rats a similar patterned bursting response occurred in the uterine nerve (UN) in response to apomorphine $\left(0.5-2.0 \mathrm{mg} \mathrm{kg}^{-1}\right.$ i.v.). Thus a common neural mechanism may regulate sexual climactic reflexes in both sexes.

British Journal of Pharmacology (2006) 148, 510-516. doi:10.1038/sj.bjp.0706763; published online 8 May 2006

Keywords: $\mathrm{D}_{2}$; ejaculation; sexual climax; apomorphine; piribedil; vas deferens; uterine

Abbreviations: MPOA, medial preoptic area; o.d., outside diameter; PCA, $p$-chloroamphetamine; PVN, paraventricular nucleus; UN, uterine nerve; VDN, vas deferens nerve

\section{Introduction}

We have previously described and characterised a series of responses associated with sexual climax following the intravenous (i.v.) administration of $p$-chloroamphetamine (PCA) in male (Stafford et al., 2003; 2006a) and female (Stafford et al., 2006b) anaesthetised rats. These in part consisted of patterned bursting activity in branches of the sympathetic hypogastric nerves innervating the vas deferens or uterine horns. The responses were shown to be representative of the neural events occurring during sexual climax. The precise pharmacological mechanism by which PCA induces such responses is not clear. However, it is possible that one or more receptors belonging to the serotonergic or dopaminergic families are responsible as PCA is known to cause an elevation in extracellular levels of both of these compounds (Steranka \& Sanders-Bush, 1977; Johnson et al., 1991; Rudnick \& Wall, 1992). Furthermore both of these transmitters have been widely implicated in the central control of sexual responses, although the detailed mechanisms have not been determined (Argiolas \& Melis, 2003; Hull et al., 2004; Paredes \& Agmo, 2004; Giuliano \& Clement, 2005). In the present study, we have investigated the question of whether dopaminergic mechanisms could be involved in the generation of the bursting patterned responses.

*Author for correspondence; E-mail: j.h.coote@bham.ac.uk
Apomorphine is a non-selective dopamine receptor agonist, which is currently used clinically as a pro-erectile drug for the treatment of erectile dysfunction. In addition to its pro-erectile properties, apomorphine has also been shown to reduce ejaculation latencies in conscious copulating rats (Tagliamonte et al., 1974; Paglietti et al., 1978; Napoli-Farris et al., 1984; Dallo et al., 1986; Clark \& Smith, 1987). It has also been used to induce ejaculation in chronic-decerebrate rats (Kaplan et al., 1991) and rats deprived of paradoxical sleep (Andersen et al., 2003). However, to our knowledge, the effects of apomorphine upon ejaculation in the anaesthetised male rat have not been reported. In this study, we have used systemic administration of apomorphine and other dopamine receptor agonists and antagonists to investigate the effects of dopamine receptor activation upon the generation of burst pattern responses in our male anaesthetised rat model. Furthermore, we have examined the effects of apomorphine in the anaesthetised female preparation to investigate whether similar dopaminergic regulatory mechanisms are present in females as males.

\section{Methods}

A total of 53 male (280-360g) and 12 female (215-245g) Wistar rats were used in this study. Animals were only used 
once and were killed at the end of the experiments using an overdose of urethane anaesthetic. All experiments conformed to the U.K. Animals (Scientific Procedures) Act 1986.

All animals were prepared and the vas deferens nerve (VDN) or uterine nerve (UN) was isolated as described in previous studies (Stafford et al., 2006a, b). Briefly, the animals were anaesthetised using gaseous 5\% enflurane and $95 \%$ oxygen. The right femoral vein and artery were cannulated and the trachea intubated. Anaesthetic was switched to i.v. urethane (Sigma, Dorset, U.K.) and the enflurane withdrawn to allow the animal to breathe naturally. A total of 1.3$1.7 \mathrm{~g} \mathrm{~kg}^{-1}$ urethane was administered initially, with top-ups of $0.1 \mathrm{ml}(25 \mathrm{mg})$ as required to maintain deep anaesthesia. The ventral surface of the abdomen was opened and the VDN or UN located, isolated and mounted upon $0.35 \mathrm{~mm}$ silver bipolar electrodes. With animals in the supine position, nerve activity, arterial blood pressure and heart rate were recorded throughout the experiments, using Chart v4.1.1. software (ADInstruments, Oxfordshire, U.K.). Following surgery animals were left to recover for approximately $30 \mathrm{~min}$, except spinally transected rats, which were allowed at least an hour recovery, prior to commencing drug administration.

\section{Experimental groups}

Apomorphine in male CNS intact rats A total of 12 male rats with intact $\mathrm{CNS}$ each received three i.v. doses of either 0.1, 0.5 or $1.0 \mathrm{mg} \mathrm{kg}^{-1}$ apomorphine, washed in with $0.1 \mathrm{ml}$ saline, at hourly intervals. Each rat was given the same dose three separate times.

Piribedil in male CNS intact rats A total of 12 male rats with intact CNS each received three i.v. doses of either 0.1, 0.5, 1.0 or $2.0 \mathrm{mg} \mathrm{kg}^{-1}$ piribedil, washed in with $0.1 \mathrm{ml}$ saline, at hourly intervals. Each rat received the same dose three separate times.

Antagonism of apomorphine-induced responses in male CNS intact rats A total of 16 male rats with intact CNS each received an administration of either $0.5 \mathrm{mg} \mathrm{kg}^{-1}$ remoxipride, $0.5 \mathrm{mg} \mathrm{kg}^{-1}$ nafadotride or $0.5 \mathrm{mg} \mathrm{kg}^{-1} \mathrm{SB} 206553$, followed $2 \mathrm{~min}$ later by an administration of $1.0 \mathrm{mg} \mathrm{kg}^{-1}$ apomorphine. Two further doses of $1.0 \mathrm{mg} \mathrm{kg}^{-1}$ apomorphine were administered at hourly intervals to test for recovery.

Apomorphine in male spinal rats In five male rats a midthoracic laminectomy and complete spinal transection (T8/ T9) was carried out following the initial cannulation. Separation of the cut ends of the spinal cord was ensured using small $(\sim 1 \mathrm{~mm})$ cotton wool balls. After a recovery period of at least $1 \mathrm{~h}$, each rat received two doses of $1.0 \mathrm{mg} \mathrm{kg}^{-1}$ apomorphine with an interval of $1 \mathrm{~h}$. After a further hour, $1.0 \mathrm{mg} \mathrm{kg}^{-1}$ PCA was administered to check the integrity of the burst pattern response.

Apomorphine in female CNS intact rats A total of 12 female rats with intact $\mathrm{CNS}$ each received three i.v. doses of either $0.5,1.0$ or $2.0 \mathrm{mg} \mathrm{kg}^{-1}$ apomorphine, washed in with $0.1 \mathrm{ml}$ saline, at hourly intervals. Each rat received the same dose three separate times. Vaginal smears were also taken to determine the stage of estrous of each rat.

\section{Compounds}

Apomorphine (Tocris, Bristol, U.K.), PCA (Sigma), piribedil $\mathrm{HCl}$ (Tocris), remoxipride $\mathrm{HCl}$ (Tocris), nafadotride (Tocris) and SB206553 (Tocris) were dissolved in physiological saline $\left(0.9 \% \mathrm{w} \mathrm{v}^{-1}\right)$. A fresh solution of apomorphine was made for each experiment. All compounds were administered i.v. via the femoral vein at a dose of $1.0 \mathrm{ml} \mathrm{kg}^{-1}$ and washed in with $0.1 \mathrm{ml}$ saline.

\section{Data analysis}

Blood pressure and heart rate were recorded throughout the experiment. Mean blood pressure values $(2 / 3 \min +1 / 3 \max )$, heart rate and nerve firing frequency were calculated using Chart software, over a period of $1 \mathrm{~min}$, pre- and postadministration of apomorphine. These values were also measured at the start and finish of experiments. These values were not significantly different at the end of the experiment in any groups. Nerve firing frequency was measured at the end of the experiment following central and peripheral crushing, and this background noise value was subtracted from all other nerve firing frequencies.

Data is presented as mean \pm s.e.m. for all administrations of each dose apomorphine. Statistical analysis was carried out using a one-way ANOVA at the 5\% significance level, with a Boneferroni's post hoc test where appropriate, for data relating to dose response experiments. Other data was analysed using a paired or unpaired $t$-test at the $5 \%$ significance level as stated.

\section{Results}

\section{Apomorphine in male CNS intact rats}

Administration of apomorphine $\left(0.1,0.5\right.$ or $\left.1.0 \mathrm{mg} \mathrm{kg}^{-1}\right)$ evoked 'typical' patterned bursting responses in the VDN, which commenced between 26 and 828 s postdrug $(241 \pm 43 \mathrm{~s})$. Responses began with a gradual rise in nerve activity, followed by $3.4 \pm 0.1$ bursts of highly synchronised activity, repeating at a frequency of $0.49 \pm 0.01$ bursts s $^{-1}$ (Figure 1). Patterned bursting responses were evoked in all 12 male CNS intact rats given apomorphine, although not after every administration (Table 1).

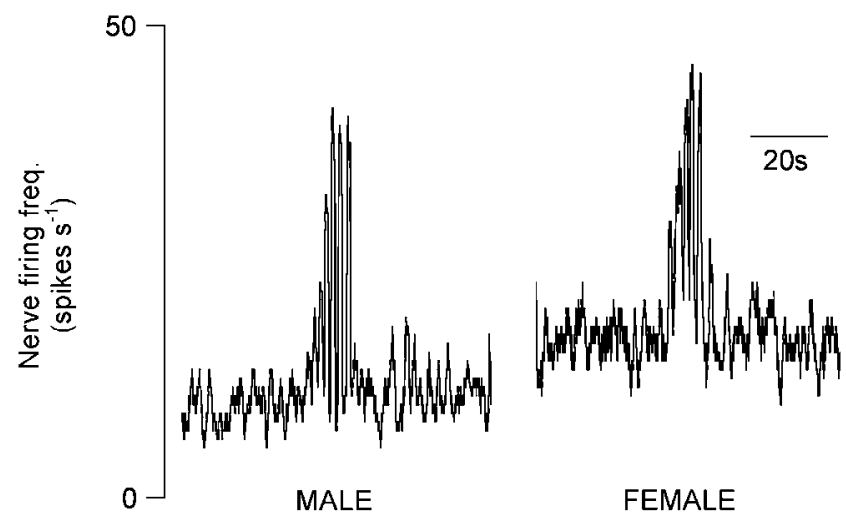

Figure 1 Typical pattern bursting responses in the VDN and UN following administration of apomorphine $\left(1.0 \mathrm{mg} \mathrm{kg}^{-1}\right.$ i.v. $)$ in male and female anaesthetised rats. 
Table 1 Summary quantifying the effects on burst pattern responses of dopamine receptor agonists and antagonists in male and female rats

\begin{tabular}{|c|c|c|c|}
\hline $\begin{array}{l}\text { Dose } \\
\left(\mathrm{mg} \mathrm{kg}^{-1}\right)\end{array}$ & $\begin{array}{l}\text { Proportion of } \\
\text { animals } \\
\text { responding }\end{array}$ & $\begin{array}{c}\text { Proportion of } \\
\text { administrations } \\
\text { eliciting responses }\end{array}$ & $\begin{array}{c}\mathrm{n} \text { (total } \\
\text { no. resp.) }\end{array}$ \\
\hline \multicolumn{4}{|c|}{ 1. Apomorphine in CNS intact male } \\
\hline 0.1 & $4 / 4$ & $5 / 12$ & 12 \\
\hline 0.5 & $4 / 4$ & $9 / 12$ & 45 \\
\hline 1.0 & $5 / 5$ & $14 / 15$ & 87 \\
\hline \multicolumn{4}{|c|}{ 2. Piribedil in CNS intact male } \\
\hline 0.1 & $2 / 3$ & $4 / 9$ & 8 \\
\hline 0.5 & $3 / 3$ & $6 / 9$ & 16 \\
\hline 1.0 & $3 / 3$ & $6 / 9$ & 19 \\
\hline 2.0 & $3 / 3$ & $7 / 9$ & 20 \\
\hline \multicolumn{4}{|c|}{ 3. Pretreatment with antagonist $+1.0 \mathrm{mg} \mathrm{kg}^{-1}$ apomorphine } \\
\hline REM 0.5 & $4 / 4$ & $7 / 12$ & 24 \\
\hline NAF 0.5 & $4 / 4$ & $7 / 12$ & 40 \\
\hline SB 0.5 & $4 / 4$ & $11 / 12$ & 66 \\
\hline \multicolumn{4}{|c|}{ 4. Apomorphine in spinal male } \\
\hline 1.0 & $0 / 5$ & $0 / 10$ & 0 \\
\hline \multicolumn{4}{|c|}{ 5. Apomorphine in CNS intact female } \\
\hline 0.5 & $2 / 4$ & $2 / 12$ & 3 \\
\hline 1.0 & $2 / 4$ & $4 / 12$ & 4 \\
\hline 2.0 & $3 / 4$ & $4 / 12$ & 6 \\
\hline
\end{tabular}

$\mathrm{REM}=$ remoxipride $\mathrm{NAF}=$ nafadotride $\mathrm{SB}=\mathrm{SB} 206553$.

A statistically significant dose-dependent relationship was observed with a greater number of responses at higher doses $(P=0.0012 ;$ Figure 2a). Despite a trend for the time to the first and last responses to decrease and increase, respectively, at the higher doses, statistical significance was not reached (Figure 3 ). All other characteristics of the responses (number of bursts, burst frequency and mean maximum firing frequency) were statistically unchanged with varying doses of apomorphine (Figures 5c, 6).

A significant hypotension of around $50 \mathrm{mmHg}$ and bradycardia of around 50 b.p.m. were observed at all doses of apomorphine (Figures 4 and $5 \mathrm{a}$ and $\mathrm{b}$ ). Blood pressure and heart rate returned to baseline over a period of approximately 5 min. During this period an immediate, but transient, significant increase in irregular baseline VDN activity was also observed, but only with 0.5 and $1.0 \mathrm{mg} \mathrm{kg}^{-1}$ apomorphine (Figure 5c). However, there was no correlation between the cardiovascular changes and the occurrence of patterned bursting responses in VDN, which often commenced during the period when blood pressure was recovering or had returned to control level. There was no significant difference between the blood pressure at the start and end of the experiment.

\section{Piribedil in male CNS intact rats}

Administration of Piribedil ( $\mathrm{D}_{2 / 3}$ agonist) elicited burst responses at all doses tested, although not in all animals or following every administration (Table 1). Despite a clear trend for an increase in the number of responses with dose, statistical significance was not reached (Figure 2b).
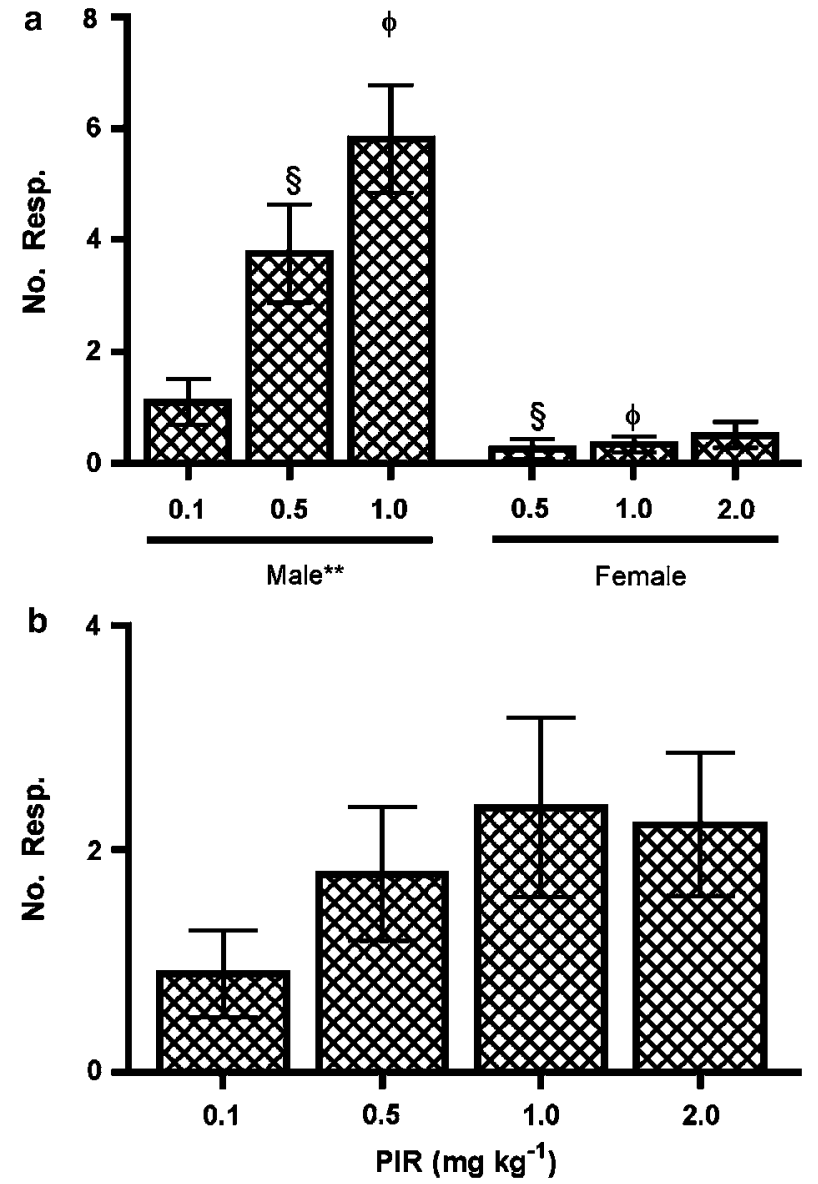

Figure 2 Number of responses induced by (a) apomorphine (APO) in males and females and (b) piribedil (PIR) in males. **indicates $P<0.01$, comparing doses in males using a one-way ANOVA. $\phi$ and $\S$ indicate $P<0.001$, comparing the same dose between sexes using an unpaired $t$-test.

Individual responses displayed a similar pattern and the characteristics were statistically unchanged between doses like those elicited by apomorphine (Figure 6).

Piribedil also caused a significant decrease in blood pressure and heart rate and increase in irregular VDN baseline activity, similar to those observed with the higher doses of apomorphine (Figure 5).

\section{Antagonism of apomorphine-induced responses in male CNS intact rats}

Pre-administration of remoxipride ( $\mathrm{D}_{2}$ receptor antagonist) and nafadotride $\left(\mathrm{D}_{3}\right.$ receptor antagonist) significantly reduced the number of burst pattern responses induced by $1.0 \mathrm{mg} \mathrm{kg}^{-1}$ apomorphine at the first administration. Responses to apomorphine had begun to recover by the time of the second administration, with a further increase in the number of responses by the time of the third administration (Figure 7). No alteration of the characteristics or timing of the burst pattern responses was observed.

Preadministration of SB206553 $\left(5-\mathrm{HT}_{2 \mathrm{C}}\right.$ receptor antagonist) had no effect on the number of responses elicited by apomorphine (Figure 7). No alteration of the characteristics or timing of the burst pattern responses was observed. 

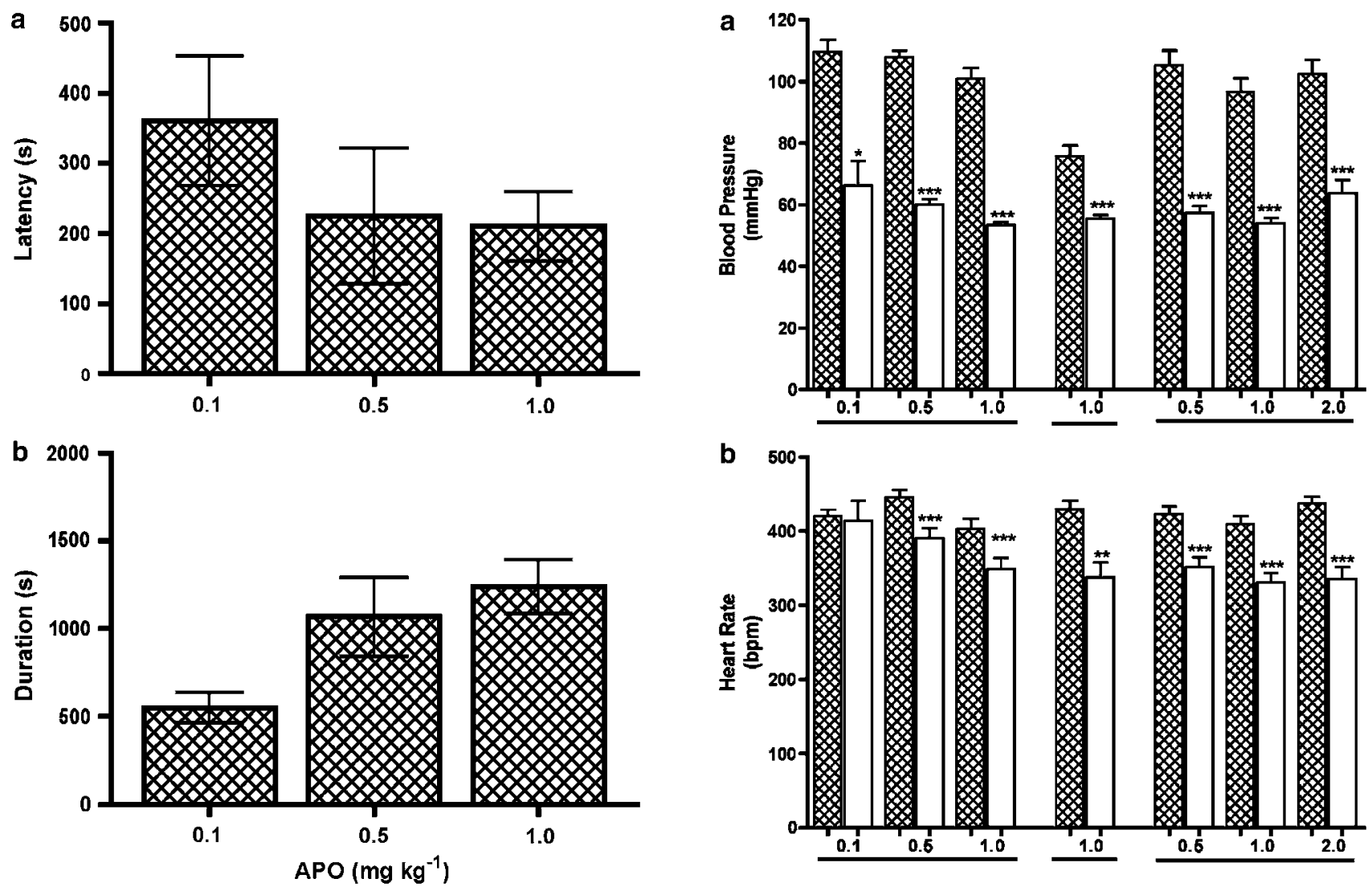

Figure 3 The effect of different doses of apomorphine on the timing of responses in CNS intact males. (a) Latency in seconds from administration to the first burst pattern response. (b) Time period from administration (duration in seconds) to the final burst pattern response.

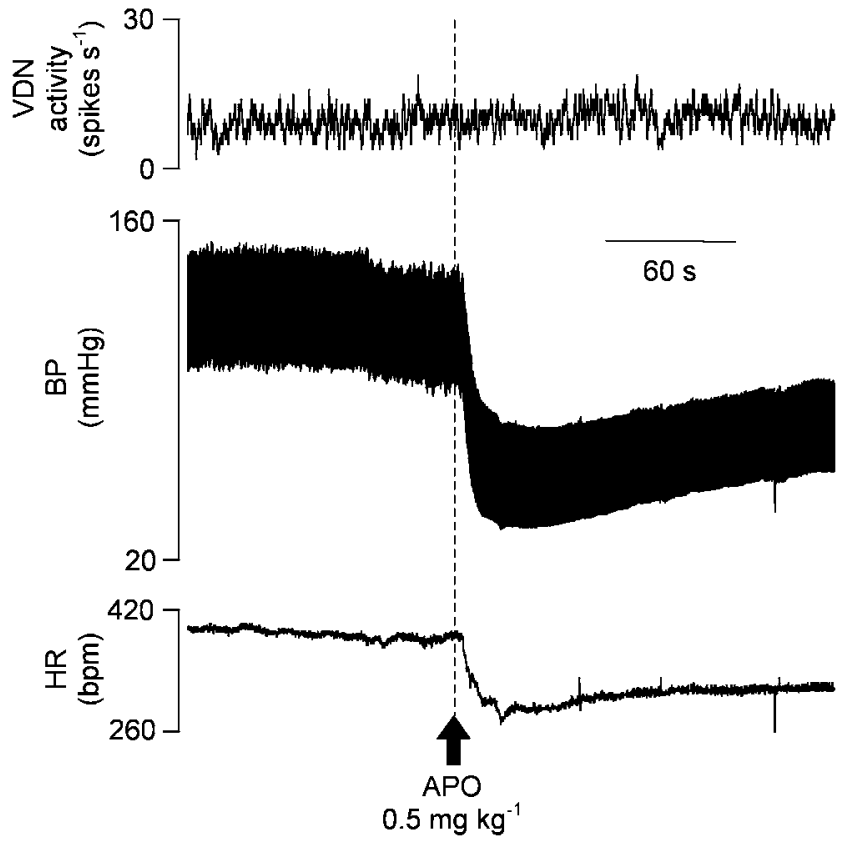

Figure 4 Effect of apomorphine (APO) on VDN firing frequency, blood pressure and heart rate. $0.5 \mathrm{mg} \mathrm{kg}^{-1}$ i.v. apomorphine was administered at time indicated by arrow.

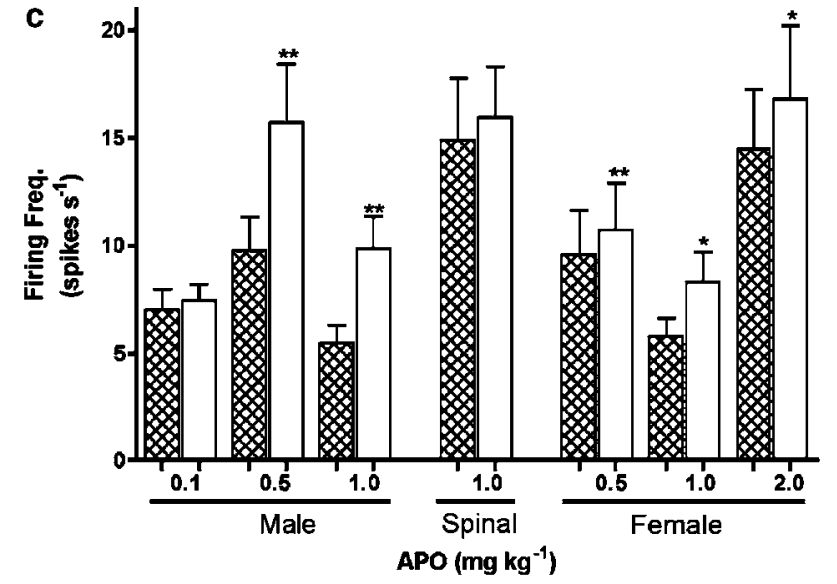

Figure 5 (a) Blood pressure, (b) heart rate and (c) nerve firing frequency before (filled bars) and after (clear bars) administration of different doses of apomorphine (APO) in the CNS intact males and females and male rats with a midthoracic spinal transection. Mean values were calculated for $1 \mathrm{~min}$ before and for a similar period commencing at $20 \mathrm{~s}$ after apomoprhine. Statistical comparisons before and after were made using the paired $t$-test. *indicates $P<0.05 ; * *$ indicates $P<0.01 ; * * *$ indicates $P<0.001$.

None of the antagonists significantly affected the blood pressure, heart rate or basal nerve activity changes observed following administration of $1.0 \mathrm{mg} \mathrm{kg}^{-1}$ apomorphine.

Apomorphine in male spinal rats

No burst pattern responses were elicited following either administration of $1.0 \mathrm{mg} \mathrm{kg}^{-1}$ apomorphine in any of the 

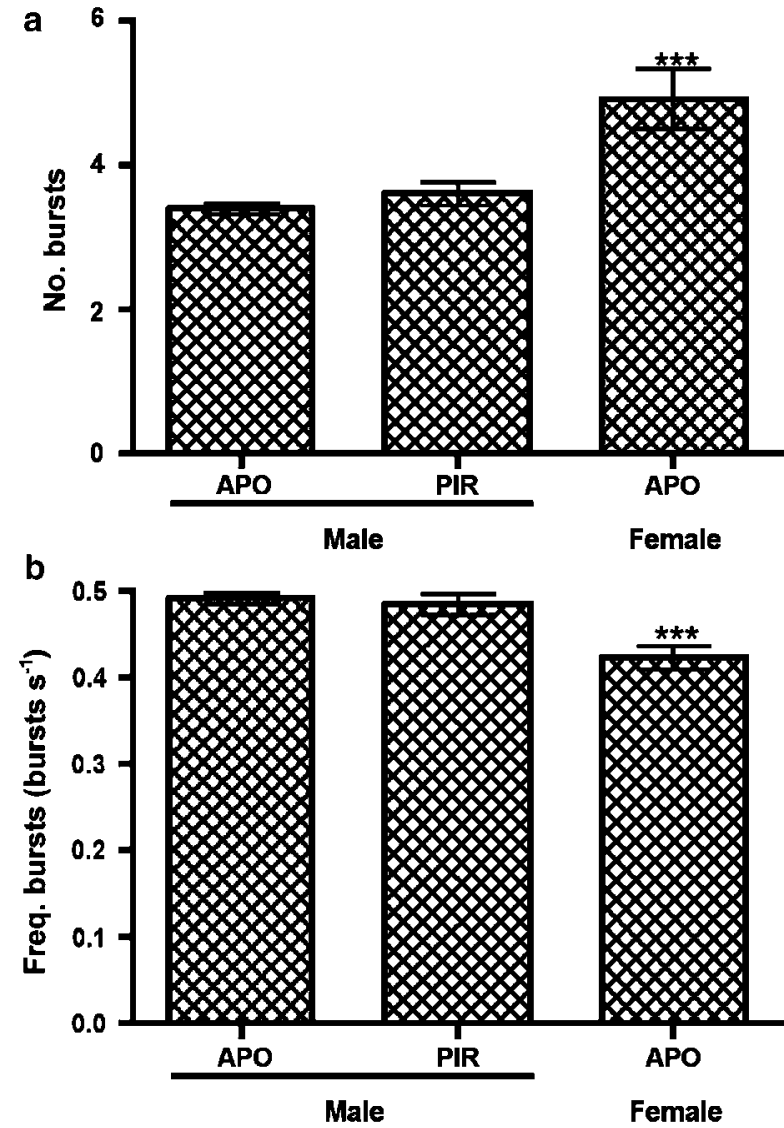

Figure 6 (a) Number and (b) frequency of highly synchronous bursts of nerve activity within pattern bursting responses following all doses of apomorphine (APO) or piribedil (PIR) in male and apomorphine in female rats. ***indicates $P<0.001$, comparing characteristics of female responses to those observed in males, using an unpaired $t$-test.

five spinal animals tested. Cardiovascular responses similar to those of intact rats were observed in the spinal rats (i.e. hypotension and bradycardia), however, an accompanying increase in nerve activity was not observed (Figure 5). In all of these five animals, a subsequent administration of PCA $\left(1.0 \mathrm{mg} \mathrm{kg}^{-1}\right)$ evoked at least one ejaculatory-like response.

\section{Apomorphine in female CNS intact rats}

Patterned bursting responses were elicited at all doses of apomorphine, although not in every rat, or following every administration (Table 1). The mean number of responses elicited in female rats at the doses tested were not statistically different $(P=0.6346$; Figure 2a). No more than two responses were elicited with any single administration of apomorphine, although a weak trend for an increase in the mean number of responses with dose could be observed. Significantly fewer responses were elicited in female rats than male rats at both the 0.5 and $1.0 \mathrm{mg} \mathrm{kg}^{-1}$ doses (Figure 2a; $P=0.0008$ and $P<0.0001$, respectively). Responses could be elicited in rats at all stages of the estrous cycle.

The characteristics of the responses (number of bursts, burst frequency and mean maximum firing frequency) were statistically unchanged with dose. Although the patterned responses

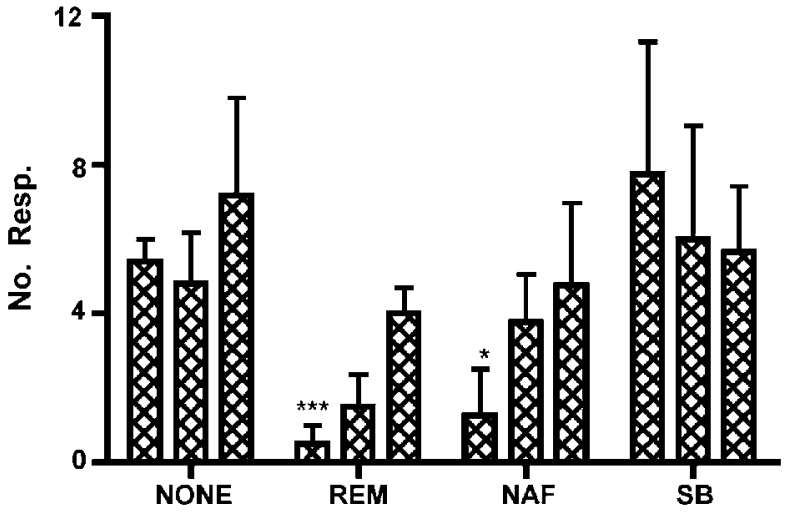

Figure 7 Number of burst pattern responses evoked by successive (left to right for each group) administrations of $1.0 \mathrm{mg} \mathrm{kg}^{-1}$ apomorphine: with no pretreatment (NONE); following a pretreatment of $0.5 \mathrm{mg} \mathrm{kg}^{-1}$ remoxipride (REM); $0.5 \mathrm{mg} \mathrm{kg}^{-1}$ nafadotride (NAF); or $0.5 \mathrm{mg} \mathrm{kg}^{-1} \mathrm{SB} 206553$ (SB). *indicates $P<0.05$, ***indicates $P<0.001$, comparing number of responses following antagonists to those following apomorphine alone using an unpaired $t$-test.

appeared qualitatively similar to those elicited by apomorphine and piribedil in males (Figure 1), statistical differences in the number $(5.0 \pm 0.4)$ and frequency $(0.42 \pm 0.01)$ of bursts per response were observed compared to males following both apomorphine and piribedil (Figure 6).

A significant hypotension and bradycardia with an accompanying increase in baseline nerve activity occurred in all animals, similar to those observed in males (Figure 5).

\section{Discussion}

These experiments on anaesthetised rats have shown that the dopamine receptor agonists, apomorphine and piribedil, given i.v. can elicit burst pattern responses in the sympathetic nerve to the VDN. These intense bursts of nerve activity have all the characteristics of responses in the VDN that are elicited by PCA (i.v.), which we have previously shown are strongly associated with contractions of the vas deferens and ejection of a seminal plug (Stafford et al., 2003; 2006a). These responses are not present in the spinal animal, but can be blocked by a pretreatment of $\mathrm{D}_{2}$-like receptor antagonists in the CNS intact animal, suggesting that activation of $\mathrm{D}_{2}$-like receptors on supraspinal neurons causes an excitation of the intraspinal neuronal network controlling sexual climax.

The doses of apomorphine used are similar to those previously shown to evoke ejaculation in restrained reflex tests (Clark \& Smith, 1987; Kaplan et al., 1991; Andersen et al., 2003). There is a clear dose response relationship for the number of responses elicited by apomorphine and a trend for the latency to the first response and last response to increase. A similar dose-dependency was observed following PCA and indicates that the response is triggered once a threshold level of excitability is reached, with such a level reached more rapidly and more frequently with higher doses of apomorphine. The possibility of a cumulative effect of apomorphine with successive administrations was dismissed as no relationship between administrations and number or latency of responses was observed. 
Apomorphine is a mixed $D_{1 / 2}$ receptor agonist with a relatively high affinity for all receptor subtypes of the dopamine family (Millan et al., 2002). However, the precise mechanisms by which apomorphine induces ejaculation have not been determined. Previous reports suggest that the facilitatory effects of apomorphine on sexual processes are potentiated by $D_{2}$ receptor activation and inhibited by $D_{1}$ receptor activation in the paraventricular nucleus (PVN) and medial preoptic area (MPOA) (Hull et al., 1989; 1992; Pehek et al., 1989b; Eaton et al., 1991). However, all of these previous investigations are complicated by dopaminergic mechanisms affecting both consummatory and appetitive behaviours (which include motivation, erection, ejaculation and reward) at various sites throughout the CNS, with consequent effects upon ejaculation. They all have also demonstrated that dopamine receptor agonists exert their effects upon erection and ejaculation in a biphasic manner, with lower concentrations affecting erection and higher concentrations affecting ejaculation. From this it was suggested that receptor populations in the MPOA control penile responses, whereas the PVN controls seminal emission (Pehek et al., 1989b). Our model is unique in that it is an anaesthetised preparation, in which erectile processes appear to be suppressed. This enables the study of ejaculatory reflexes without the complication of other reflexes or behaviours that may influence the regulation of ejaculation. Therefore this allows the clarification of the specific role of dopaminergic mechanisms with regard to ejaculation alone.

Remoxipride is a $\mathrm{D}_{2}$ receptor antagonist with selectivity over $\mathrm{D}_{3}$ and $\mathrm{D}_{4}$ receptors $\left(K_{\mathrm{i}}\right.$ values of around 300,1600 and $2800 \mathrm{nM}$, respectively, Mohell et al., 1993). Nafadotride is a highly potent selective $\mathrm{D}_{3}$ antagonist that is centrally active following systemic administration $\left(K_{\mathrm{i}}\right.$ values for nafadotride are $0.52,5$ and $269 \mathrm{nM}$ for human cloned $\mathrm{D}_{3}, \mathrm{D}_{2}$ and $\mathrm{D}_{4}$ receptors, respectively, Audinot et al., 1998). The antagonism of responses to $1.0 \mathrm{mg} \mathrm{kg}^{-1}$ apomorphine by both of these receptor antagonists suggest that $D_{2}$-like receptors have a large excitatory role in the generation of the patterned bursting responses in the VDN. However, at the concentrations tested and the relative selectivity of the antagonists for these receptor subtypes it is difficult to be sure a single $\mathrm{D}_{2}$-like receptor subtype is responsible. Nonetheless the action of piribedil (a mixed $\mathrm{D}_{2 / 3}$ receptor agonist), at a concentration shown to induce ejaculation in the chronic sleep deprived rat (Andersen \& Tufik, 2005), to induce burst pattern responses adds weight to the argument for an excitatory action of $\mathrm{D}_{2}$-like receptors.

We have previously shown that PCA or the combination of $5-\mathrm{HT}_{1 \mathrm{~A}}$ and $5-\mathrm{HT}_{2 \mathrm{C}}$ receptor agonists will elicit the bursting responses in CNS intact and spinal rats (Stafford et al., 2003; 2006a). Furthermore, we hypothesised the presence of a descending excitatory 5-hydroxytyptaminergic pathway acting upon postsynaptic $5-\mathrm{HT}_{2 \mathrm{C}}$ receptors in the lumbosacral spinal cord (Stafford et al., 2006a). Therefore, in the study presented here, we tested whether apomorphine causes the activation of such a pathway using a pretreatment of SB206553 (a 5- $\mathrm{HT}_{2 \mathrm{~B} / \mathrm{C}}$ receptor antagonist) at a dose previously shown to block $5-\mathrm{HT}_{2 \mathrm{C}}$ receptor agonist induced burst pattern responses. SB206553 failed to block the response to apomorphine suggesting that apomorphine does not activate the excitatory 5-hydroxytryptaminergic pathways that act at postsynaptic $5-\mathrm{HT}_{2 \mathrm{C}}$ receptors in the lumbosacral spinal cord.
No responses were observed in spinal rats following the administration of the highest dose of apomorphine. This was not because of a deterioration in the animal's condition since responses were subsequently induced by PCA in the same animals, also dismissing the possibility that the neural networks were compromised in these animals. Therefore, the evidence suggests that the primary site of action of apomorphine is at supraspinal sites, and these are distinct from those affected by 5-hydroxytryptaminergic compounds. This is indirectly supported by previous investigations that have shown intrathecal administration of apomorphine do not facilitate seminal emission (Pehek et al., 1989a), whereas intracranial administration does (Pehek et al., 1989b). The findings presented here also demonstrate the possibility that a part of the excitatory action of PCA may be through the activation of supraspinal dopamine receptors, as PCA has been reported to cause the release of dopamine in addition to 5-HT (Steranka \& Sanders-Bush, 1977).

The bursting pattern responses observed in female rats were similar to those previously elicited by PCA, which were associated with other physiological sexual responses (Stafford et al., 2006b), and to those observed in males. This suggests that a similar excitatory dopaminergic mechanism for sexual reflexes is also present in female rats. However, the female rats appeared to be much less responsive than males to apomorphine at the same doses, as fewer females responded and fewer responses were observed in those responding females. An explanation may be that the neuronal circuitry is less excitable in females, either due to differences in dopamine receptor populations or a stronger inhibition of the neuronal network for sexual climax. Further investigations using selective dopamine receptor agonists and antagonists should assist in revealing any such differences in receptor populations between sexes.

Beach (1967) suggested that sex hormones influence sexual excitability. In the present study with a limited number of rats there was no correlation between the stages of oestrous and numbers of burst pattern responses observed.

The number and frequency of bursts within patterned responses were similar following both piribedil and apomorphine at all doses tested and even after preadministration of the various antagonists. Furthermore these characteristics were similar to those previously observed following PCA and the 5-HT agonists. The pattern sequence was also similar in female rats. This supports our suggestion that these climacticlike responses have a common neural basis in both sexes and are generated following the activation of a common pattern generator in the lumbosacral spinal cord. However, a quantitative difference in the number and frequency of bursts was observed between males and females, suggesting subtle differences between sexes in the duration of the climactic response.

The data show that administration of apomorphine causes a rapid hypotension and bradycardia. The mechanisms of these cardiovascular actions of apomorphine are not clear, but may be best explained by Lahlou (2003), who investigated the effect of intrathecal administration of apomorphine on heart rate and aortic pressure in the rat. Lahlou concluded that separate inhibitory actions of apomorphine on sympathetic preganglionic neurones to the vasculature and heart caused the hypotensive and bradycardic responses, respectively. 
The increase in irregular nerve activity corresponding in timing to the cardiovascular responses may represent a vasomotor component of the sympathetic activity in the nerve. However, it is also possible that this represents an increase in motor activity to the internal sex organs. We have previously suggested that a small component of activity in the VDN was likely to represent vasomotor activity, but the majority was efferent activity to the internal sex organs (Stafford et al., 2006a). Furthermore, the results presented here show that although these nerve activity changes were statistically significant, the increase in activity is only a fraction of both basal activity and that observed during the synchronous bursts of nerve activity.

\section{References}

ANDERSEN, M.L. \& TUFIK, S. (2005). The effects of dopaminergic agonists on genital reflexes in paradoxical sleep-deprived male rats. Physiol. Behav., 84, 205-210 [E-pub 2004 Dec 19].

ANDERSEN, M.L., BIGNOTTO, M. \& TUFIK, S. (2003). The effect of apomorphine on genital reflexes in male rats deprived of paradoxical sleep. Physiol. Behav., 80, 211-215.

ARGIOLAS, A. \& MELIS, M.R. (2003). The neurophysiology of the sexual cycle. J. Endocrinol. Invest., 26, 20-22.

AUDINOT, V., NEWMAN-TANCREDI, A., GOBERT, A., RIVET, J.M., BROCCO, M., LEJEUNE, F., GLUCK, L., DESPOSTE, I., BERVOETS, K., DEKEYNE, A. \& MILLAN, M.J. (1998). A comparative in vitro and in vivo pharmacological characterization of the novel dopamine D3 receptor antagonists (+)-S 14297, nafadotride, GR 103,691 and U 99194. J. Pharmacol. Exp. Ther., 287, 187-197.

BEACH, F.A. (1967). Cerebral and hormonal control of reflexive mechanisms involved in copulatory behavior. Physiol. Rev., 47, 289-316.

CLARK, J.T. \& SMITH, E.R. (1987). Effects of apomorphine on sexual behavior in young and middle-aged rats. Neurobiol. Aging, $\mathbf{8}$, 153-157.

DALLO, J., LEKKA, N. \& KNOLL, J. (1986). The ejaculatory behavior of sexually sluggish male rats treated with (-)deprenyl, apomorphine, bromocriptine and amphetamine. Pol. J. Pharmacol. Pharm., 38, 251-255.

EATON, R.C., MARKOWSKI, V.P., LUMLEY, L.A., THOMPSON, J.T., MOSES, J. \& HULL, E.M. (1991). D2 receptors in the paraventricular nucleus regulate genital responses and copulation in male rats. Pharmacol. Biochem. Behav., 39, 177-181.

GiUliano, F. \& CLEMENT, P. (2005). Physiology of ejaculation: emphasis on serotonergic control. Eur. Urol., 48, 408-417.

HULL, E.M., EATON, R.C., MARKOWSKI, V.P., MOSES, J., LUMLEY, L.A. \& LOUCKS, J.A. (1992). Opposite influence of medial preoptic D1 and D2 receptors on genital reflexes: implications for copulation. Life Sci., 51, 1705-1713.

HULL, E.M., MUSCHAMP, J.W. \& SATO, S. (2004). Dopamine and serotonin: influences on male sexual behavior. Physiol. Behav., 83, 291-307.

HULL, E.M., WARNER, R.K., BAZZETT, T.J., EATON, R.C., THOMPSON, J.T. \& SCALETTA, L.L. (1989). D2/D1 ratio in the medial preoptic area affects copulation of male rats. J. Pharmacol. Exp. Ther., 251, $422-427$.

JOHNSON, M.P., CONARTY, P.F. \& NICHOLS, D.E. (1991). [ $\left[{ }^{3} \mathrm{H}\right]$ monoamine releasing and uptake inhibition properties of 3,4-methylenedioxymethamphetamine and $p$-chloroamphetamine analogues. Eur. J. Pharmacol., 200, 9-16.

KAPLAN, J.M., HAO, J.X. \& SODERSTEN, P. (1991). Apomorphine induces ejaculation in chronic decerebrate rats. Neurosci. Lett., 129, 205-208.

LAHLOU, S. (2003). Mechanisms underlying the cardiovascular responses to spinal dopamine receptor stimulation by apomorphine in anesthetized rats. Neurosci. Lett., 335, 187-191.
The findings of this study suggest that dopaminergic mechanisms cause an alteration in the excitability of the pattern generator for sexual climax. This may be an important factor to consider when prescribing dopaminergic compounds to treat disease, in particular the use of apomorphine to treat erectile dysfunction. Furthermore the results suggest that dopamine receptors may be a suitable target for compounds in the treatment of ejaculatory and orgasmic dysfunctions in males and females, respectively.

The work presented in this paper was funded by Plethora Solutions Ltd.

MILLAN, M.J., MAIOFISS, L., CUSSAC, D., AUDINOT, V., BOUTIN, J.A. \& NEWMAN-TANCREDI, A. (2002). Differential actions of antiparkinson agents at multiple classes of monoaminergic receptor. I. A multivariate analysis of the binding profiles of 14 drugs at 21 native and cloned human receptor subtypes. J. Pharmacol. Exp. Ther., 303, 791-804.

MOHELl, N., SALlEMARK, M., ROSQVist, S., MALMBERG, A., HOGBERG, T. \& JACKSON, D.M. (1993). Binding characteristics of remoxipride and its metabolites to dopamine D2 and D3 receptors. Eur. J. Pharmacol., 238, 121-125.

NAPOLI-FARRIS, L., FRATTA, W. \& GESSA, G.L. (1984). Stimulation of dopamine autoreceptors elicits 'premature ejaculation' in rats. Pharmacol. Biochem. Behav., 20, 69-72.

PAGlietTI, E., QUARANTOTTI, B.P., MEREU, G. \& GESSA, G.L. (1978). Apomorphine and L-DOPA lower ejaculation threshold in the male rat. Physiol. Behav., 20, 559-562.

PAREDES, R.G. \& AGMO, A. (2004). Has dopamine a physiological role in the control of sexual behavior? A critical review of the evidence. Prog. Neurobiol., 73, 179-226.

PEHEK, E.A., THOMPSON, J.T. \& HULL, E.M. (1989a). The effects of intracranial administration of the dopamine agonist apomorphine on penile reflexes and seminal emission in the rat. Brain Res., 500, 325-332.

PEHEK, E.A., THOMPSON, J.T. \& HULL, E.M. (1989b). The effects of intrathecal administration of the dopamine agonist apomorphine on penile reflexes and copulation in the male rat. Psychopharmacology. (Berlin), 99, 304-308.

RUDNICK, G. \& WALL, S.C. (1992). p-Chloroamphetamine induces serotonin release through serotonin transporters. Biochemistry, 31, 6710-6718.

STAFFORD, S.A., BOWERY, N.G. \& COOTE, J.H. (2003). p-Chloroamphetamine-induced activity in the vas deferens and associated sympathetic nerve activity in the anaesthetised rat. J. Physiol., 552P, C83.

STAFFORD, S.A., BOWERY, N.G., TANG, K. \& COOTE, J.H. (2006a) Activation by $p$-chloroamphetamine (PCA) of the spinal ejaculatory pattern generator in anaesthetized male rats. Neuroscience, (in press).

STAFFORD, S.A., TANG, K. \& COOTE, J.H. (2006b). Sympathetic genital responses induced by $p$-chloroamphetamine (PCA) in anaesthetised female rats. Neuroscience, 138, 725-732.

STERANKA, L. \& SANDERS-BUSH, E. (1977). Temporal effects of p-chloroamphetamine on catecholamine synthesis. Eur. J. Pharmacol., 45, 83-86.

TAGLiAMONTE, A., FRATTA, W. \& GESSA, G.L. (1974). Aphrodisiac effect of L-DOPA and apomorphine in male sexually sluggish rats. Experientia, 30, 381-382.

(Received November 11, 2005 Revised February 28, 2006 Accepted March 23, 2006

Published online 8 May 2006) 